\title{
Properties of Czech WW2 Concrete Fortifications after 80 Years
}

\author{
Ondřej Holčapek ${ }^{1}$, Pavel Reiterman ${ }^{2}$ and Jiří Pazderka ${ }^{3}$ \\ ${ }^{1}$ Experimental Centre, Faculty of Civil Engineering, Czech Technical University in Prague (CTU), \\ Thákurova 7, 16629 Prague 6, Czech Republic, ondrej.holcapek@fsv.cvut.cz \\ ${ }^{2}$ Experimental Centre, Faculty of Civil Engineering, Czech Technical University in Prague (CTU), \\ Thákurova 7, 16629 Prague 6, Czech Republic, pavel.reiterman@fsv.cvut.cz \\ ${ }^{3}$ Department of Building Structures, Faculty of Civil Engineering, Czech Technical University in \\ Prague (CTU), Thákurova 7, 16629 Prague 6, Czech Republic, jiri.pazderka@fsv.cvut.cz
}

\begin{abstract}
This paper deals with the investigation of properties of Czech fortification concrete bunkers built before Second World War (WWII). The Czech defense system consisted mainly of light bunkers type No. 37. The vast numbers of these bunkers have been preserved in various conditions to nowadays. The light bunkers type No. 37 were designed to last limited lifetime of decades. According to the preserved test protocols, strength of used concrete varied from 40 to $50 \mathrm{MPa}$, measured on cube specimens with dimensions $200 \times 200 \times 200 \mathrm{~mm}$. There is an information, in general public, about high quality and strength of used concrete. The non-destructive analysis of compressive strength, determined by Schmidt hammer was performed. This method was used to maintain a historical value of the structures. Three were analyzed different bunkers type No. 37 located in Western Bohemia - Pilsner region. Tested bunkers are preserved in various conditions with various quality of concrete. The measurements by Schmidt hammer took place in several locations especially in the interior part. The exterior was also investigated but only in the locations of surface which were not covered with camouflage plaster. Non-destructive testing had shown high quality of concrete older than 80 years old concrete, with compressive strength between 50 to $60 \mathrm{MPa}$. On the other hand, based on the visual assessment, the concrete showed very different characteristics, especially in compactness and the quality of surface layer. We can find places with insufficiently compacted concrete with exposed steel reinforcement.
\end{abstract}

Keywords: Concrete, Fortification, WW2, Non-Destructive Testing, Schmidt Hammer.

\section{Introduction}

The European continent has a great historical, cultural and architectural heritage, which includes monuments dated back several centuries and even millennia. The architectural heritage contains relicts of ancient civilizations, medieval buildings, sacral and also profane buildings. In the terms of building monuments, materials used most frequently are bricks or stone masonry, timber and steel (traditional and proven materials). The field of architectural heritage is closely connected with the restoration, reconstruction and, if necessary, strengthening. The strengthening and conservation of widely used structural elements (column, pillar, vault, beam etc.) made with traditional materials is well described and mastered. Even modern materials with high utility properties are successfully implemented into the strengthening process - we can find the application of carbon rods or fabrics (Witzany et al., 2016, Jongsung et al., 2005). Even very modern material - textile reinforced concrete can be used for stabilization or 
strengthening of masonry structures (Garmendia et al., 2014).

Even relatively new buildings and structures are in the center of interest of exploration and conservation. We can see a growing interest in exploring industrial heritage as a reflection of its time. This brings new challenges for historians, architects and engineers. A very good example of this phenomenon is the system of the Czech fortification system, built by former Czechoslovakian government in years before the WWII. This example of widespread use of concrete has been extensively preserved in various conditions till today. For general public, concrete is not the representative of historical material (Heinemann et al., 2008).

\subsection{Czech Fortification System}

The system of fortification was built in relatively short time during 1930s by incurring high financial and material costs. The whole system consisted of several defensive lines of light bunkers for seven soldiers. In this way, the strategic disadvantage of defending very long borders with Germany, Poland and later with Austria and Hungary, with limited human capacity, had been solved. This system of light bunkers had been supplemented in certain places, usually in mountainous terrain by artillery fortresses. The support of the defense system contains large number of smaller fortresses, usually connected by system of underground corridors. Unlike the bunkers type No. 37, these fortresses were intended for long-term stay of military crews. The bunkers type No. 37 were designed for short stay of soldiers only at the time of threat. Due to their cramped space, longer stay of crews was not possible. In the event of war crash, bunkers No. 37 were designed forindirect firing, when individual fine fans of each
bunker overlap with the fire fans of jits neighbor. The front wall was the strongest part of
fortification and it was also protected for exterior part by a stone flat with loam (also used as
camouflage).
The vast majority of the preserved bunkers No. 37, according to cadastral information, are
owned by the Army of ezech Republic. More extensive preserved complexes and artilley forts have a status of official cultural heritage and are open to the public. A large number of objects

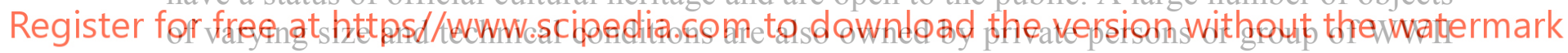

fans. These organizations or individualities usually try to restore the bunker to its original state, including camouflage, armament and equipment. However, with more intensive use and reconstruction works, there are many challenges that need to be solved. The bunkers were not designed for long-term stay of military crew. Various problems are connected with the actions of capillarity and moisture penetration. An extensive experiment and numerical simulation on this topic performed Pazderka et al., 2016. The problem with massive water ingress can be solved by using modern crystallizing coating (Pazderka et al.,2019). On these two examples we can see that the issue of defensive structures gains its importance, therefore the theoretical investigation and field in-situ survey are also significant and important.

\section{Performed Investigation and Observation}

Three preserved examples of bunkers No. 37 located in the "Pilsner line" in West Bohemia region were chosen for the purpose of this contribution. The designations of investigated bunkers are D-19/22/A-160, D-19/47/A-160 and D-20/4/A-160. This number has its systems and contains the information about location and type of object. The first part "D-19" or "D-20" means the construction section, in this case "Nové Městečko" respectively "Blažim". It was 
usually named about the nearest important city or village. The next number, in our case " 22 ", "47" and " 4 " means the order of the bunker in the particular construction section. The last part, in this case "A-160" means the type of bunker. Letter "A" means, that the investigated bunkers represent the most commonly used type with ordinary ballistic resistance. There were also bunkers with letter " $Z$ ", which describes the bunker with higher ballistic resistance with stronger front wall. The last number characterizes the angle of coverage with installed machine guns.

\subsection{Testing by Schmidt Hammer}

Testing by Schmidt hammer represents commonly used method for non-destructive testing of concrete's mechanical properties. This method is standardized and allowed by standard systems of many countries. There have been cases where Schmidt hammer was used as representative of non-destructive method for measurement of compressive strength of masonry elements (Aliabdo et al., 2012). However, the most widespread use still represent concrete, as a material usually supplemented by destructive testing if circumstances permit (Holčapek et al., 2014). The standard Schmidt hammer type N was used, according to Czech standard (CSN EN 2013). Due to the preserved external plasters the investigation took place mainly in the interior part. The schematic cross-section of bunker No. 37 with marked location of performed measurements is shown on Figure 1. Minimum of 50 measurements were performed on each place (places in different heights). Also the quality of roof was investigated.
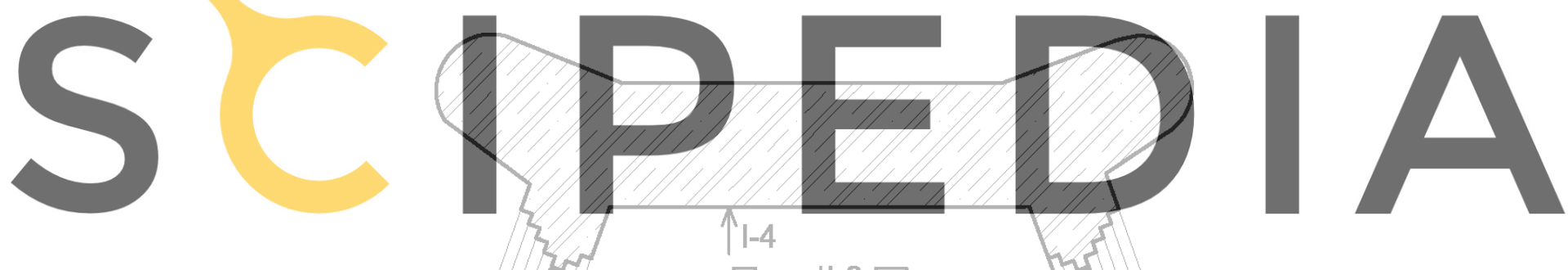

Register for free at https//wwurscypedia.con to downlolad the Wersign without the watermark

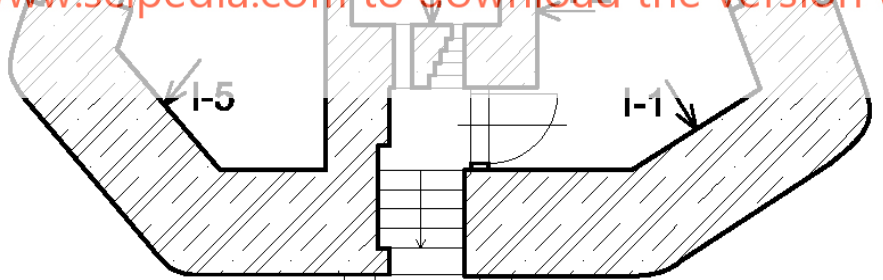

Figure 1. Schematic cross-section with marked places of performed measurements.

\subsection{Visual Evaluation}

Analyzed bunkers are situated in one location and were built in approximately in the same period of second half of 1937. Their entrances are not locked, which means that the bunkers are not protected against vandalism. We can still observe the residua of original timber cladding in the interior part, as shown on Figure 2 and also on Figure 3. These timber elements were exposed to moisture and the effects of fungi and microorganisms. An important finding is that the quality of concrete within a single object is variable. We can observe excellent quality of surface layer, without any cracks or cluster of aggregate. There are places with very poor quality 
of compaction in the same bunker. We can see reinforcement uncoated by concrete, clusters of coarse aggregate and other imperfections. This surface was originally covered by timber cladding and the estimated designed lifetime was only about 20 years, bud if we want to preserved these objects to future generations, we have to deal also with these problems.

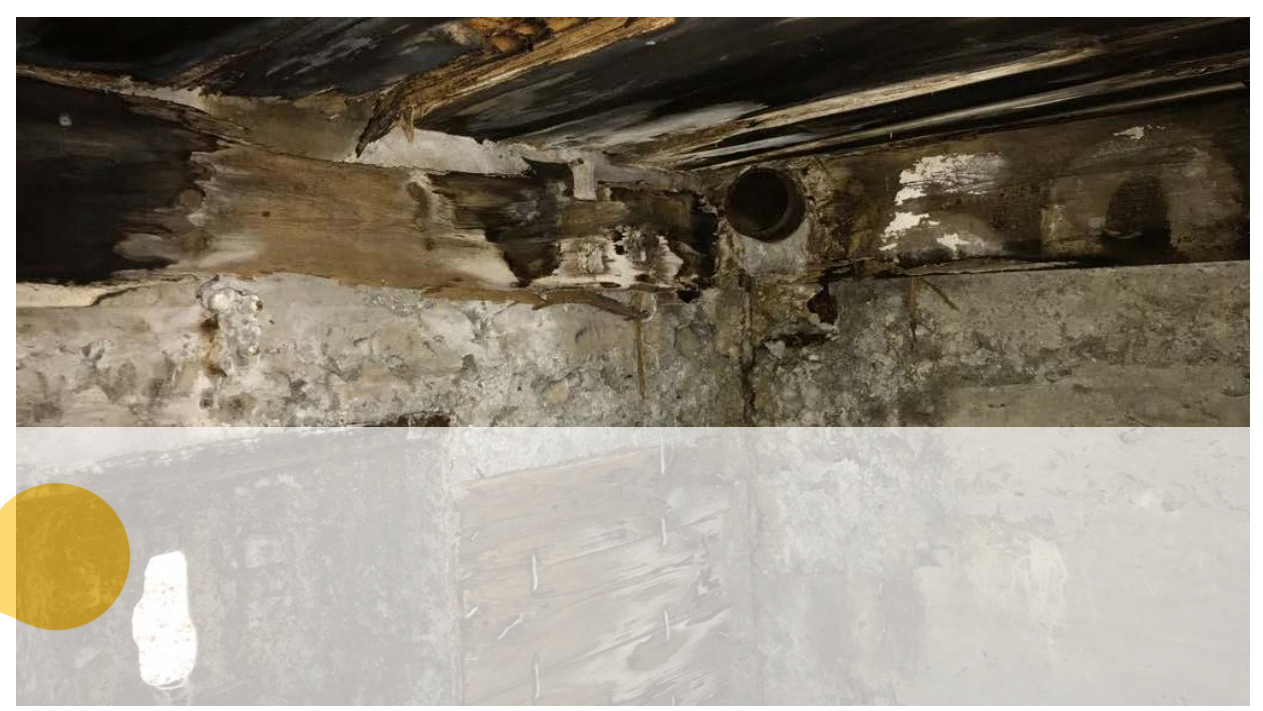

Figure 2. Residuum of internal timber cladding, poor quality of surface layer of concrete.
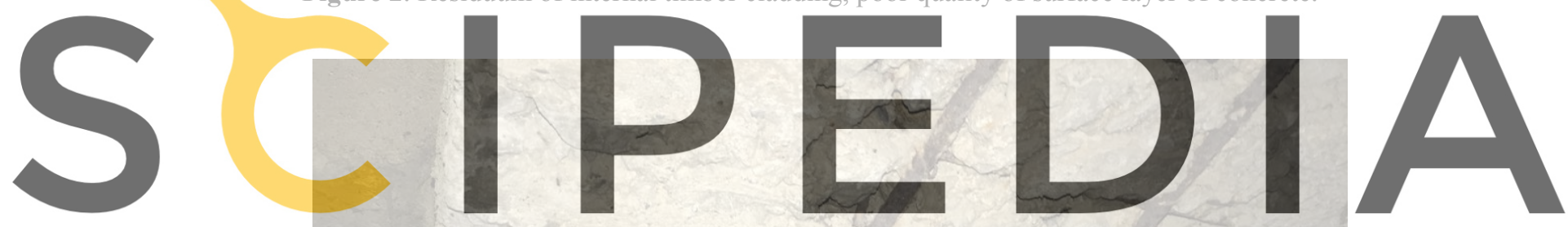

Register for free at https//www.scipedia.com to download the version without the watermark

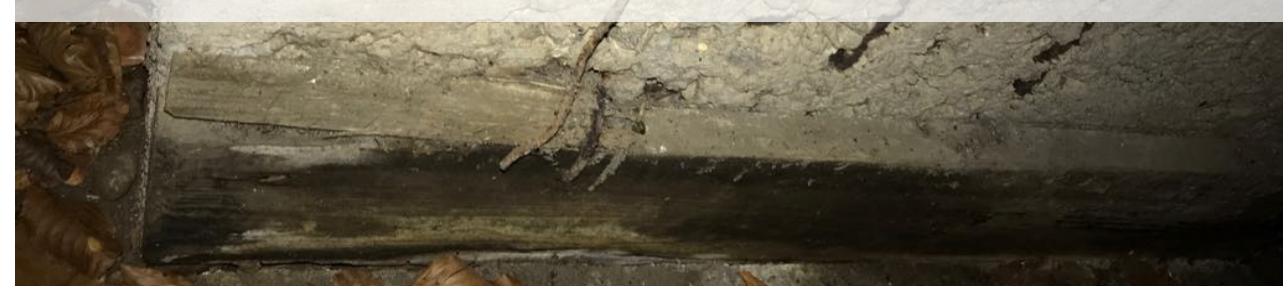

Figure 3. Insufficient compaction with uncovered steel reinforcement.

\section{Results and Discussion}

As mentioned above, totally six different locations in the interior part were investigated by Schmidt hammer. The investigation in exterior part is limited by the protective earth wall in the front part and also by the residues of masking plasters, but one location was also analyzed.

All results of performed measurements are summarized in Table 1. The first column describes the location according to Figure 1. Following three columns list the values of tentative 
compressive strength of three different bunkers No. 37. The last row in the table contains the compressive strength calculated according to destructive test performed in 1937 on cube specimens with dimension $200 \times 200 \times 200 \mathrm{~mm}$.

Table 1. Results of performed non-destructive measurements.

\begin{tabular}{cccc}
\hline Designation & $\mathrm{D}-19 / 22 / \mathrm{A}-160$ & $\mathrm{D}-19 / 47 / \mathrm{A}-160$ & $\mathrm{D}-20 / 4 / \mathrm{A}-160$ \\
\hline & {$[\mathrm{MPa}]$} & {$[\mathrm{MPa}]$} & {$[\mathrm{MPa}]$} \\
\hline Exterior & 67.5 & 59.7 & $\mathrm{~N} / \mathrm{A}$ \\
\hline Interior (I-1) & 58.1 & 54.3 & 57.8 \\
\hline Interior (I-2) & 51.7 & 48.8 & 53.4 \\
\hline Interior (I-3) & 56.3 & 63.4 & 59.6 \\
\hline Interior (I-4) & 61.2 & 68.9 & 57.8 \\
\hline Interior (I-5) & 53.9 & 59.9 & 64.7 \\
\hline Interior (roof) & 59.4 & 58.6 & 53.1 \\
\hline Compressive strength (test & 49.5 & 57.5 & 51.4 \\
performed in 1937 & & & \\
\hline
\end{tabular}

The strength in the exterior part of investigated bunker D-200/4/A-160 could not be measured due to well preserved camouflage plasters on the walls. There were several places on remaining two bunkers, where the plasters did not preserve and it was possible do a measurement of the concrete wall directly. The properties of concrete in the exterior part can be influenced by the carbonation process that caused increased strength of the surface layer,
where the measurement took place. It is recommended to mechanically remove thin part of
carbonated layer. Considering the non-indasive approach to testing, this recommen dation was
not chosen. Each value from interior part represents an average of at least 50 measurentents.
A relatively small spread of values can be observed.

\section{or freend hitp'ps//www.scipedia.com to download the version without the watermark}

Based on performed non-destructive testing of compressive strength, determined by Schmidt hammer, in different location of light bunkers knows as "Model No. 37" and also according to visual evaluation we can obtain following conclusions:

- The non-destructive testing of compressive strength of concrete plays its important role for determination tentative quality of concrete structures. The importance of nondestructive testing is increasing in the case of historically valuable structures that we do not want or cannot damage. Obtained values showed high strength of over 80 years old concrete and confirmed the strength determined in 1930s on specimens with dimension $200 \times 200 \times 200 \mathrm{~mm}$ (according to the army methodology used before WWII).

- The quality of concrete from investigated bunkers shows very different properties. On one object, we can find areas with excellent surface quality and well compacted concrete. These locations alternate areas with exposed reinforcement and insufficiently compacted concrete with large gaps. This phenomenon is caused by the originally used method of compaction with rammer in 1930s. The exposed and uncovered reinforcement is not a result of concrete's degradation.

- Durability of concrete is very important and currently discussed parameter. In the case 
of studied bunkers No. 37 the durability is closely connected with long-term properties of concrete and steel reinforcement. All these parameters are connected with the function of waterproofing (foundations and roof). According to performed in-situ investigations the biggest problems connected with durability are leaches of minerals from concrete. Due to the age of structures (over 80 years) extensive carbonation of concrete can be expected, which is also related to the corrosion of steel reinforcement with insufficient concrete cover layer. Based on the performed analysis (visual evaluation and the Schmidt hammer measurements) we can expect long service life and good durability of bunkers No. 37. At the same time is necessary to provide further moisture penetration into the structure - restoration of the waterproofing function of roof and insulation of foundations from moisture. Due to the age of bunkers, we can identify problems, that affect the overall service life and durability which can be solved by repairs and reconstruction works and precautions.

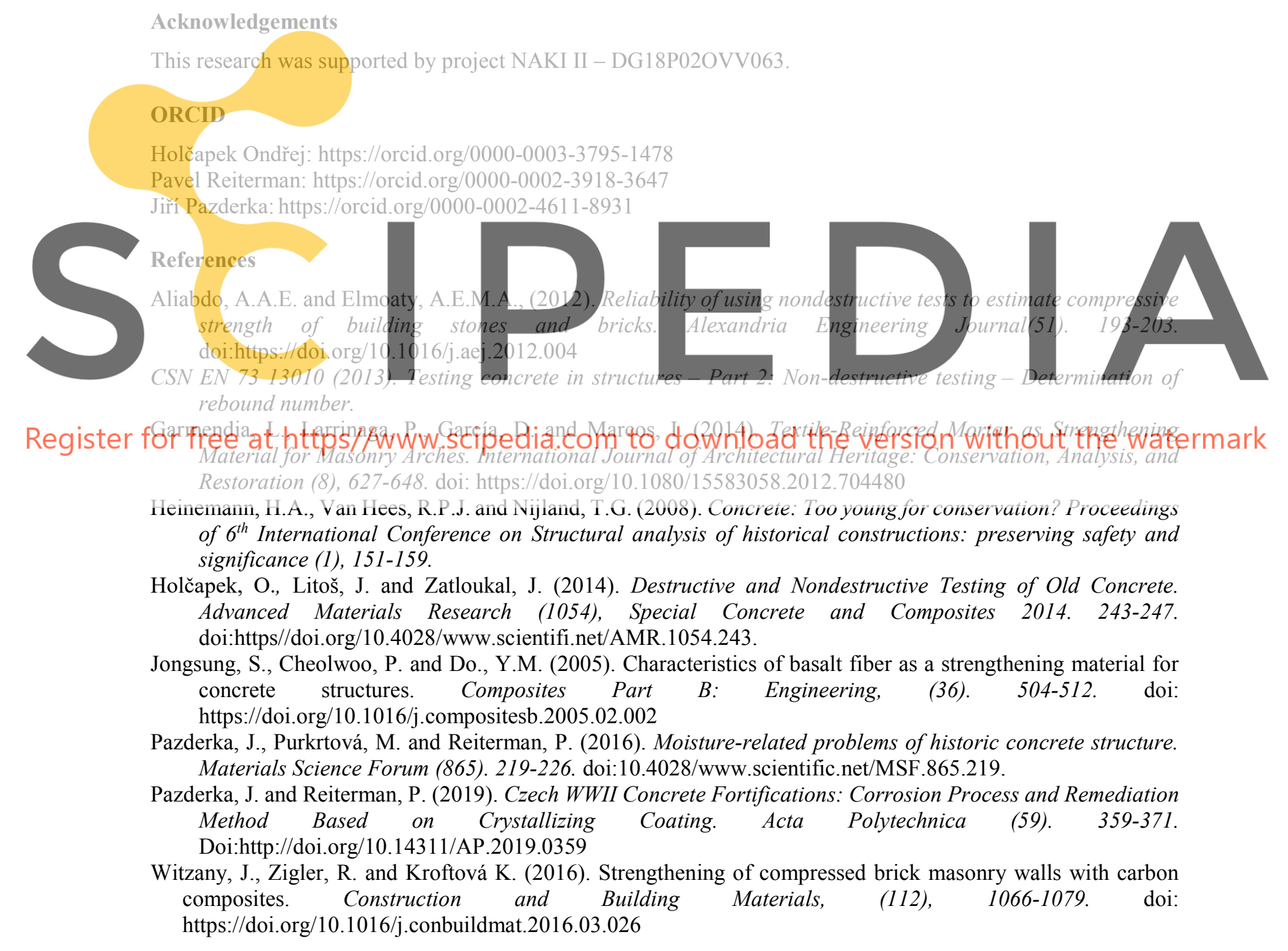

